\title{
DISPOSIÇÃO AFETIVA PARA O CUIDADO NA RECUPERAÇÃO: O COTIDIANO DA EQUIPE DE ENFERMAGEM
}

\author{
Compassionate care in surgical patient recovery: the daily nursing team
}

\section{Disposición afectiva para la atención en la recuperación: el equipo diario de enfermería}

\author{
Pâmela Maiara Grison' ${ }^{\circledR}$, Denise Consuelo Moser Aguiar ${ }^{2}$ (๑), \\ Gelson Aguiar da Silva Moser $^{3} \oplus$, Marceli Cleunice Hanauer ${ }^{4} \oplus$, Suelem Klein ${ }^{5} \oplus$
}

RESUMO: Objetivo: Discutir a implementação dos protocolos para o cuidado ao paciente na sala de recuperação pós-anestésica, considerando a disposição afetiva da equipe de enfermagem no seu cotidiano, em um hospital da região oeste de Santa Catarina. Método: Pesquisa qualitativa, com base na etnografia e na observação participante. Os sujeitos da pesquisa foram nove profissionais da enfermagem. Os dados foram coletados no primeiro semestre de 2019, considerando-se a análise de conteúdo de Bardin, de onde emergiram três categorias. Resultados: Os profissionais de enfermagem compreendem a importância da disposição afetiva no cuidado aos pacientes na recuperação, elencando a alta demanda de atividades e cirurgias e o número de funcionários insuficiente como dificuldades para um cuidado afetivo, efetivo e empático em seu cotidiano. Há baixa adesão aos protocolos assistenciais disponibilizados no setor, apesar do reconhecimento de sua importância no cuidado direcionado aos pacientes. Conclusão: Como fatores determinantes apresentaram-se a alta demanda diária do setor, o quantitativo de funcionários inadequado e o atendimento a pacientes críticos por longos períodos na recuperação anestésica. Palavras-chave: Avaliação em enfermagem. Sala de recuperação. Cuidados de enfermagem. Afeto.

ABSTRACT: Objective: The aim of this study was to discuss the implementation of protocols for patient care in the postanesthesia care unit, considering the provision of compassionate care by the nursing team in their daily routine, in a hospital in the western region of Santa Catarina, Brazil. Method: Qualitative study based on ethnography and participant observation. The research subjects were nine nursing professionals. Data were collected in the first half of 2019, considering Bardin's content analysis, from which three categories emerged. Results: Nursing professionals understand the importance of providing compassion in patient care during recovery, listing the high demand for activities and surgeries and the insufficient staff as difficulties for providing compassionate and effective care in their daily routine. There is low adherence to the assistance protocols available in this unit, despite the recognition of their importance in patient care. Conclusion: Limiting factors for compassionate care of patients in postanesthesia recovery were the high daily demand in this unit, inadequate staff and care of critical patients for long periods.

Keywords: Nursing assessment. Recovery room. Nursing care. Compassion.

RESUMEN: Objetivo: Discutir la implementación de protocolos para el cuidado del paciente en la sala de recuperación postanestésica, considerando la disposición afectiva del equipo de enfermería en su vida diaria, en un hospital en el oeste de Santa Catarina. Método: Investigación cualitativa, basada en etnografía y observación participante. Los sujetos de investigación fueron nueve profesionales de enfermería. Los datos se recopilaron en la primera mitad de 2019, considerando el análisis de contenido de Bardin, del cual surgieron tres categorías. Resultados: Los profesionales de enfermería entienden la importancia

'Enfermeira assistencial do Hospital Unimed - Chapecó (SC), Brasil.

2Doutora em Educação. Professora adjunta da Universidade Federal da Fronteira Sul (UFFS) - Chapecó (SC), Brasil.

${ }^{3}$ Mestranda em Enfermagem. Professora substituta da UFFS - Chapecó (SC), Brasil.

¿Doutor em Enfermagem. Professor adjunto da UFFS - Chapecó (SC), Brasil.

${ }^{5}$ Especialista em Enfermagem. Enfermeira do Hospital da Unimed - Chapecó (SC), Brasil.

*Autora correspondente: denise.moser@uffs.edu.br

Recebido: 02/01/2020 - Aprovado: 21/07/2020

https://doi.org/10.5327/Z1414-4425202000030006 
de la disposición afectiva en la atención al paciente en recuperación, enumerando la alta demanda de actividades y cirugías y el número insuficiente de empleados, como dificultades para la atención afectiva, efectiva y empática en su vida diaria; baja adherencia al uso de protocolos de atención disponibles en el sector, a pesar del reconocimiento de su importancia en la atención dirigida a los pacientes. Conclusión: Como factores determinantes fueron la alta demanda diaria en el sector, el número inadecuado de empleados y la atención de pacientes críticos durante largos períodos en la recuperación anestésica. Palabras clave: Evaluación en enfermería. Sala de recuperación. Atención de enfermería. Afecto.

\section{INTRODUÇÃo}

O período de recuperação do paciente compreende desde o momento de saída da sala operatória até a alta do usuário da sala de recuperação pós-anestésica (SRPA). Nesse período, é necessário que toda a equipe seja atuante no cuidado do paciente, oferecendo suporte em suas necessidades, além da observação contínua de sua evolução, já que ele precisa recuperar o nível de consciência e alcançar a estabilização homeostática e de todos os parâmetros vitais. Por isso, a equipe precisa desempenhar cuidados contínuos e individualizados, que tenham como meta recuperar a saúde e prevenir riscos ${ }^{1}$.

Como o paciente passa por toda uma alteração na fisiologia do seu corpo durante o procedimento cirúrgico, bem como no equilíbrio dos seus sistemas, o cuidado dispensado pela enfermagem mostra-se extremamente relevante, principalmente na SRPA, onde ele se encontra diante de vários riscos no pós-operatório, necessitando de cuidado atento e integrado. Nesse sentido, a atenção dispensada na recuperação busca proporcionar segurança, prevenir e identificar complicações e instabilidade do quadro clínico do paciente e saber como agir nesses casos ${ }^{2}$.

Como fator integrante de um cuidado bem articulado, é indispensável compreender como o paciente se vê, estando mergulhado na tensão existente no ambiente hospitalar, principalmente na SRPA. Ao deparar com a experiência cirúrgica, o paciente sofre um corte do seu cotidiano usual para dissociar-se nesse outro mundo, o qual pode propiciar experiências prazerosas ou desconfortáveis, e vivenciar procedimentos invasivos no seu corpo e na sua intimidade, seja na sala operatória, seja na sala de recuperação, no período pós-operatório imediato (POI). Ele passa a enfrentar uma rotina de cuidados e vivências que não ultrapassa os limites do seu próprio leito, os quais perduram durante toda a internação ${ }^{3}$.

O cotidiano vivenciado na SRPA é citado pela maioria dos profissionais de enfermagem como uma das principais dificuldades enfrentadas no que tange à qualidade do cuidado. Apesar de configurar um inconveniente para a equipe, o cotidiano apresenta-se como oportunidade de desenvolver novas estratégias para reformular o modo de cuidar, por meio do toque respeitoso e do carinho para com o outro. Nesse sentido, exige qualificação específica dos profissionais, visando ao cuidado humanizado, acolhedor e individual ${ }^{4}$.

Para que esse cuidado na SRPA possa ser efetivo, antes de mais nada é necessário número adequado de profissionais, de modo que a demanda seja distribuída igualmente e que o atendimento se apoie rigorosamente nas normas e nos protocolos instituídos no setor. Para que o cuidado possa ser sistematizado de acordo com as necessidades de cada paciente, faz-se preciso o uso de protocolos, como a avaliação de vias aéreas, respiração e circulação (ABC) na admissão inicial do paciente, com abordagem craniopodálica, visando à identificação dos parâmetros iniciais pós-anestesia, o checklist adotado com base no índice de Aldrete e Kroulik modificado, a escala de sedação de Ramsey, o índice de Steward e a escala de avaliação da dor, todos decisivos no momento da alta ${ }^{5}$.

Nesse sentido, no intuito de compreender como se dá essa relação, surge a seguinte questão-problema: como o uso de protocolos, normas e rotinas norteia a disposição afetiva para cuidar do paciente na SRPA?

\section{OBJETIVO}

Discutir o uso dos protocolos e das normas para o cuidar do paciente na SRPA, considerando a disposição afetiva da equipe de enfermagem no seu cotidiano.

\section{MÉTODO}

Esta pesquisa faz parte de um estudo maior intitulado "Corpo e corporeidade no cotidiano do centro cirúrgico: bordando o cuidado e a formação no labirinto da equipe de enfermagem”, o qual foi institucionalizado e recebeu aprovação ética do comitê de ética em pesquisa da Universidade Federal da Fronteira do Sul(UFFS), Chapecó, Santa Catarina, sob parecer n ${ }^{\circ} 3.130 .487$.

Trata-se de um estudo do tipo etnográfico, com abordagem qualitativa, a qual estuda o mundo de significados 
e as relações humanas, bem como a realidade humana na sociedade $^{6}$. Já o estudo etnográfico trabalha com o estabelecimento de relações para eleger informantes, transcrever textos, levantar hipóteses, mapear campos específicos, imergir-se nas atividades do cotidiano, relatando-as em diário de campo, cuja coleta de dados é feita com descrição minuciosa da rotina vivida pelos seres humanos envolvidos na pesquisa ${ }^{7}$.

Desenvolveu-se o estudo na SRPA do centro cirúrgico (CC) de um hospital do oeste de Santa Catarina, na qual atuam em média 18 profissionais de enfermagem. Os sujeitos da pesquisa foram nove desses profissionais, sendo um enfermeiro e dois técnicos de enfermagem por turno. Cabe destacar que os demais não apresentaram disponibilidade para participar da pesquisa.

A coleta dos dados foi realizada na unidade do CC, na SRPA, nos meses de maio e junho de 2019, em períodos de manhã, tarde e noite alternados. Os instrumentos de coleta de dados foram uma entrevista semiestruturada e um diário de campo, preenchido mediante observação participante.
O tratamento dos dados deu-se por meio da análise de conteúdo de Bardin $^{8}$, seguindo estas etapas:

- organização da análise;

- codificação;

- categorização;

- tratamento dos resultados, inferência e interpretação dos resultados.

\section{RESULTADOS}

Considerando-se as falas e as percepções dos entrevistados, foram criadas três categorias com base nos principais elementos e temas emergidos nas entrevistas, que compuseram os seguintes capítulos: atuação da equipe de enfermagem em relação às normas e protocolos da SRPA; um olhar para a afetividade no cuidado de enfermagem na SRPA; um cuidado efetivo na SRPA: possibilidade?

Tais categorias estão apresentadas, a seguir, nos Quadros 1, 2 e 3.

Quadro 1. Categorização das normas e protocolos.

\begin{tabular}{|c|c|c|c|}
\hline $\begin{array}{l}\text { Categoria / } \\
\text { Capítulo }\end{array}$ & $\begin{array}{l}\text { Unidade de } \\
\text { registro }\end{array}$ & Falas dos sujeitos & Observações \\
\hline \multirow{3}{*}{$\begin{array}{l}\text { Capítulo } 1 \\
\text { Atuação da equipe } \\
\text { de enfermagem } \\
\text { em relação } \\
\text { às normas e } \\
\text { protocolos da } \\
\text { SRPA }\end{array}$} & \multirow{3}{*}{$\begin{array}{l}\text { - Sobrecarga } \\
\text { - Falta de } \\
\text { funcionários } \\
\text { - Observação } \\
\text { - Atentar aos } \\
\text { riscos } \\
\text { - Suporte da } \\
\text { equipe } \\
\text { - Trabalho em } \\
\text { equipe } \\
\text { - Cotidiano } \\
\text { agitado } \\
\text { - Demanda } \\
\text { - Rotina } \\
\text { cansativa } \\
\text { - Fluxo de } \\
\text { pacientes } \\
\text { - Estrutura física } \\
\text { - Funcionários }\end{array}$} & $\begin{array}{l}\text { P1: “A equipe da manhã é mais resistente à rotina nova, algum } \\
\text { protocolo novo que a gente vai inserir, eles são um pouco mais } \\
\text { resistentes. À tarde não, à tarde é bem tranquilo, o que tu pro- } \\
\text { por para eles, eles fazem, eles geralmente não questionam, não } \\
\text { se opõem, assim, eles respeitam a hierarquia um pouco mais } \\
\text { do que a manhã. A manhã vai, mas assim, meio que aos tran- } \\
\text { cos, tu tens que gerenciar conflitos daí com a equipe da manhã." }\end{array}$ & \multirow{3}{*}{$\begin{array}{l}\text { - Rotina mecanizada e não } \\
\text { interação com os pacientes } \\
\text { - Atraso na verificação de } \\
\text { sinais vitais } \\
\text { - Falta de explicação } \\
\text { sobre os procedimentos } \\
\text { realizados } \\
\text { - Falta de explicações } \\
\text { para questionamentos } \\
\text { realizados pelos pacientes } \\
\text { - Relações de poder } \\
\text { - Falta de uso dos } \\
\text { protocolos pela equipe } \\
\text { - Liberação de pacientes } \\
\text { pelo anestesista } \\
\text { baseada somente na } \\
\text { análise de sinais vitais, } \\
\text { - ou no questionamento } \\
\text { ao paciente sobre } \\
\text { sua capacidade } \\
\text { de movimentar os } \\
\text { membros inferiores } \\
\text { Relação conturbada com } \\
\text { alguns profissionais } \\
\text { refletindo na forma de } \\
\text { oferecer assistência }\end{array}$} \\
\hline & & $\begin{array}{l}\text { P2: “A equipe segue bem certinho as rotinas, as normas solici- } \\
\text { tadas, os protocolos também. Se eu tiver um paciente grave, às } \\
\text { vezes a gente tem paciente de UTI também, né, e eu não con- } \\
\text { sigo dar atenção aos demais, os colegas assumem, vão dar } \\
\text { uma mão, ajudar, nunca é deixado algum paciente com dor, é } \\
\text { dada a atenção necessária. Até aquela parede do } 13 \text { ao } 18 \text { era só } \\
\text { externo, aí a pessoa que estava lá se sobrecarregava muito, né, } \\
\text { porque tem que dar dieta, tem que levantar, tem um monte de } \\
\text { coisas que você tem que fazer nessas quatro horas, um monte } \\
\text { de medicação. E agora os externos vão ficar meio distribuídos, } \\
\text { daí todo mundo vai conseguir trabalhar." }\end{array}$ & \\
\hline & & $\begin{array}{l}\text { P3: “É uma equipe unida, a gente se ajuda bastante, desde rece- } \\
\text { ber um paciente, de aprazar, de cuidar, enfim, tudo, né. As nos- } \\
\text { sas rotinas estão mudando muito, mas a gente está tentando } \\
\text { se adaptar da melhor maneira possível para sempre prestar } \\
\text { o cuidado ao paciente, e elas já estão mudando para atender } \\
\text { melhor o paciente, para não deixar o paciente muito tempo espe- } \\
\text { rando, com dor, enfim, para melhorar o atendimento. A forma } \\
\text { de receber e distribuir os pacientes, antes recebiam todos na } \\
\text { parede do um ao quatro, hoje em dia não, é um por parede, }\end{array}$ & \\
\hline
\end{tabular}


Quadro 1. Continuação.

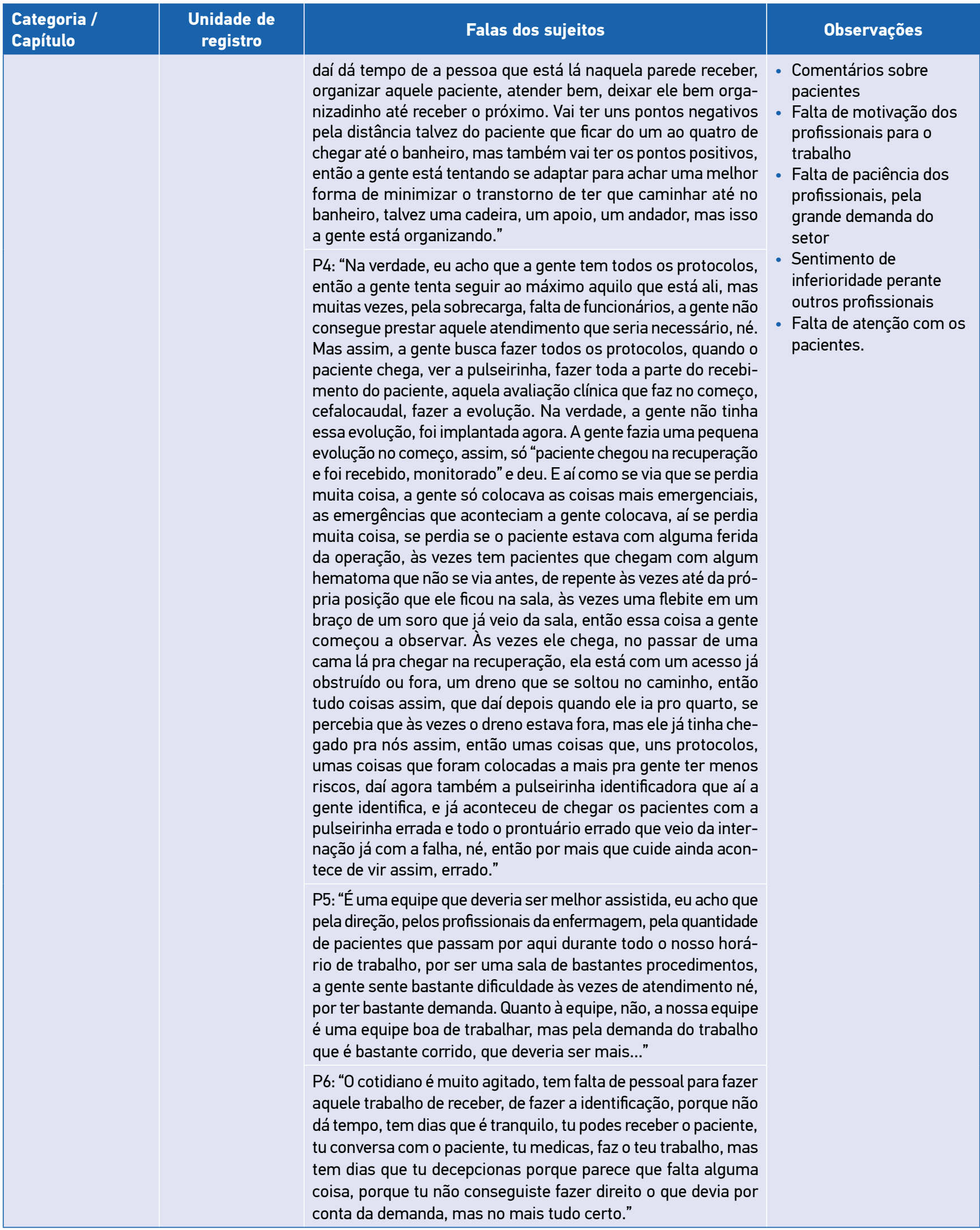


Quadro 1. Continuação.

\begin{tabular}{|l|l|l|}
\hline $\begin{array}{l}\text { Categoria / } \\
\text { Capítulo }\end{array}$ & $\begin{array}{c}\text { Unidade de } \\
\text { registro }\end{array}$ & Falas dos sujeitos \\
\hline & $\begin{array}{l}\text { P7: “É uma rotina bem puxada, porque o hospital não colabora, } \\
\text { estávamos em cinco funcionárias e agora estamos em três, a } \\
\text { enfermeira é bem-disposta a ajudar a gente a fazer tudo. A rotina } \\
\text { é sempre a mesma, é puxado quando tem paciente de UTI, aqui } \\
\text { é uma semiUTI quando não tem leito na UTI, já teve dias que } \\
\text { tinha sete pacientes de UTI e tem que dar conta, e mãe com cesá- } \\
\text { rea e bebê misturado com UTI e com paciente pós-operatório." }\end{array}$ \\
\hline $\begin{array}{l}\text { P8: “É que nem a gente estava falando antes, a questão do coti- } \\
\text { diano aqui é bem corrida, é um fluxo muito grande de pacientes. } \\
\text { De dia até tem mais funcionários, mas de noite são poucos, e } \\
\text { assim, naquela correria. É receber paciente, anotar sinais, medi- } \\
\text { car, trocar soro, ver como está o curativo e deu, não tem como } \\
\text { fazer nada mais. Quanto a normas e rotinas, a maioria a gente } \\
\text { não consegue cumprir, por que não tem funcionários o sufi- } \\
\text { ciente, a gente faz o básico mesmo, mais não tem como fazer." }\end{array}$ & $\begin{array}{l}\text { Pq: “A condição física do ambiente, pouco funcionário. A hora } \\
\text { que a gente chegou, só eu e ela no salão cheio, um pouco aten- } \\
\text { dia aqui, um pouco lá, quando tu via lá já estava tudo atrasado, } \\
\text { aqui tinha que fazer, daí é difícil assim, né, então as vezes até } \\
\text { tu pensas em ser um pouquinho melhor, no caso, tentar fazer } \\
\text { um pouquinho melhor, mas chega na hora e não tem como." }\end{array}$ \\
\hline
\end{tabular}

SRPA: sala de recuperação pós-anestésica; UTI: unidade de terapia intensiva.

Quadro 2. Categorização da afetividade no cuidado.

\begin{tabular}{|c|c|c|c|}
\hline $\begin{array}{l}\text { Categoria / } \\
\text { Capítulo }\end{array}$ & $\begin{array}{l}\text { Unidade de } \\
\text { registro }\end{array}$ & Falas dos sujeitos & Observações \\
\hline \multirow{3}{*}{$\begin{array}{l}\text { Capítulo } 2 \\
\text { Um olhar para } \\
\text { a afetividade } \\
\text { no cuidado de } \\
\text { enfermagem na } \\
\text { SRPA }\end{array}$} & \multirow{3}{*}{$\begin{array}{l}\text { - Cuidado } \\
\text { - Dificuldade } \\
\text { afetiva } \\
\text { - Empatia } \\
\text { - Equipe } \\
\text { colaborativa } \\
\text { - Colaboração } \\
\text { entre a equipe } \\
\text { - Conforto do } \\
\text { paciente } \\
\text { - Mais assistência } \\
\text { - Previsão de } \\
\text { riscos } \\
\text { - Atenção a } \\
\text { sintomas } \\
\text { - Oferecer o } \\
\text { melhor de si } \\
\text { - Assistir o } \\
\text { paciente } \\
\text { - Agilidade no } \\
\text { atendimento } \\
\text { - Atenção } \\
\text { - Gostar do que } \\
\text { faz }\end{array}$} & $\begin{array}{l}\text { P1: "Eu acho que, das duas equipes, assim, todos eles têm, } \\
\text { eu acho, uma forma de cuidar adequada, assim, tem algumas } \\
\text { exceções, na minha opinião, mas eu acho que é meio pessoal, } \\
\text { assim, de personalidade de uma ou duas pessoas que eu tenho } \\
\text { na equipe da manhã que eu sinto mais dificuldade, assim, na } \\
\text { parte afetiva, sabe, às vezes de sentir empatia, de se colocar no } \\
\text { lugar do outro, sabe, eu acho que de manhã eu consigo perce- } \\
\text { ber que tem um pouquinho mais disso. De tarde, não, assim, a } \\
\text { equipe da tarde, como ela é colaborativa, ela é mais unida, ela } \\
\text { é diferente, então nessa parte eles saem ganhando um pouqui- } \\
\text { nho também, sabe, sobre a parte afetiva." }\end{array}$ & \multirow{3}{*}{$\begin{array}{l}\text { - Pouca afetividade com } \\
\text { os pacientes } \\
\text { - Comentários inadequados } \\
\text { - Pouca interação com os } \\
\text { pacientes } \\
\text { - Falta de diálogo na } \\
\text { recepção dos pacientes } \\
\text { - Falta de explicações } \\
\text { sobre medicações e } \\
\text { procedimentos } \\
\text { - Falta de paciência com } \\
\text { pacientes e familiares } \\
\text { - Imposição de conduta } \\
\text { sem conversar/explicar } \\
\text { ao paciente } \\
\text { - Esquecimento de } \\
\text { medidas de conforto } \\
\text { - Disposição diminuída } \\
\text { para o trabalho } \\
\text { - Pouca compreensão da } \\
\text { situação do paciente } \\
\text { - Falta de proatividade de } \\
\text { alguns profissionais } \\
\text { - Pouco diálogo }\end{array}$} \\
\hline & & $\begin{array}{l}\text { P2: "Acho que é mais ou menos que nem nós comentamos agora, } \\
\text { a disposição quando um está ocupado, outro ajuda, se preci- } \\
\text { sar medicar, vai e medica, não é porque o paciente é do outro } \\
\text { que não vai medicar, um ajuda o outro. Vai atrás de resolver." }\end{array}$ & \\
\hline & & $\begin{array}{l}\text { P3: “O paciente referiu dor, por mais que não seja eu que esteja } \\
\text { com aquele leito ou o colega está ocupado, ou está lanchando, } \\
\text { ou está em algum lugar, eu vou lá ou qualquer um vai lá, vê a } \\
\text { medicação, pede se tem alergia, enfim, toda a nossa rotina, } \\
\text { os cuidados são administrados, não é deixado o paciente sem } \\
\text { medicar, ou sem talvez alcançar um copo de água se pode, ou } \\
\text { enfim. O que estiver ao nosso alcance, para o melhor conforto } \\
\text { do paciente, seria isso." }\end{array}$ & \\
\hline
\end{tabular}


Quadro 2. Continuação.

\begin{tabular}{|c|c|c|c|}
\hline $\begin{array}{l}\text { Categoria / } \\
\text { Capítulo }\end{array}$ & $\begin{array}{l}\text { Unidade de } \\
\text { registro }\end{array}$ & Falas dos sujeitos & Observações \\
\hline & \multirow[t]{4}{*}{$\begin{array}{l}\text { - Sentir-se feliz } \\
\text { - Cuidar com } \\
\text { carinho } \\
\text { - Atenção ao } \\
\text { paciente } \\
\text { - Contato com o } \\
\text { paciente } \\
\text { - Prioridades } \\
\text { - Conversar com } \\
\text { o paciente e } \\
\text { ouvir queixas } \\
\text { - Cuidados } \\
\text { gerais } \\
\text { - Trabalho } \\
\text { bem-feito } \\
\text { - Atenção }\end{array}$} & $\begin{array}{l}\text { P4: “A gente tenta prestar o melhor possível, mas como falta } \\
\text { funcionário, precisava mais assistência, às vezes tu está sobre- } \\
\text { carregada, está com um paciente de UTI e mais quatro, e daí tu } \\
\text { não consegue dar aquela assistência, nem para aquele de UTI } \\
\text { como deveria, nem para os outros, então também é uma coisa } \\
\text { que vai ter que ser melhorada, mas a gente tenta as rotinas cada } \\
\text { dia ir melhorando, às vezes quando a gente tá sem enfermeira a } \\
\text { gente procura a gente mesmo fazer a nossa rotina, nosso traba- } \\
\text { lho, não para porque tá sem enfermeira, e às vezes a gente pro- } \\
\text { cura o enfermeiro lá dentro, e sempre percebendo as coisas que } \\
\text { podem acontecer, a gente fica atento aos sintomas que podem } \\
\text { levar talvez a uma parada, por que ele tá sudorético? Por que a } \\
\text { pressão está baixa ou alta? Em cesáreas a gente cuida muito do } \\
\text { sangramento para que não venha a chocar. Muitas vezes já aconte- } \\
\text { ceu de só de estar atento ali, evitar de elas ter uma parada, então } \\
\text { são coisas que a gente vai buscando melhorar cada dia mais." }\end{array}$ & \multirow[t]{4}{*}{$\begin{array}{l}\text { Falta de vigilância com } \\
\text { os pacientes. }\end{array}$} \\
\hline & & $\begin{array}{l}\text { P5: "Eu acho que com tudo que a gente procura dar o melhor } \\
\text { da gente, de si, mas eu acho que ainda a gente falha em alguns } \\
\text { pontos, né, ainda precisaria ser mais bem assistido o paciente, } \\
\text { na agilidade, às vezes tem alguns reclamando de dor e a gente } \\
\text { demora um pouco pra atender porque a demanda é muito grande, } \\
\text { não sempre, mas alguns dias é bem difícil, tipo hoje tá tranquilo, } \\
\text { hoje tu consegue dar mais atenção, mas tem dias que é bem } \\
\text { difícil, principalmente aos sábados, porque no sábado fica uma } \\
\text { equipe só, que é de cinco pessoas, nos horários de almoço tem } \\
\text { que redividir, aí às vezes você consegue medicar o paciente, } \\
\text { mas tu demora pra voltar lá pra ver se a dor aliviou, se passou } \\
\text { a náusea, nesses pontos aí." }\end{array}$ & \\
\hline & & $\begin{array}{l}\text { P6: “Essa parte aqui é bem pessoal, porque assim, vai de cada } \\
\text { um, de cada profissional. Tem profissional que está no lugar } \\
\text { errado e não se dá conta e não sei por quê. A gente nota quando } \\
\text { a gente não gosta do que faz, a pessoa tem que estar fazendo } \\
\text { o trabalho dela e tem que estar feliz. Desde uma pergunta feita } \\
\text { pelo paciente, tem pacientes que chegam aqui e fazem um } \\
\text { monte de perguntas, o porquê disso, o porquê daquilo, por- } \\
\text { que tem uns que chegam aqui, por conta da própria anestesia } \\
\text { eles nem sabem que fizeram cirurgia, mas 'que horas vou fazer } \\
\text { cirurgia', 'quanto tempo vai levar', aí a gente explica que ele já } \\
\text { fez cirurgia, que ele já está na recuperação, que vai ficar tan- } \\
\text { tas horas, que qualquer coisa é pra chamar, e a gente nota que } \\
\text { nessa parte a pessoa tem que ser técnica, pra você olhar, dar } \\
\text { um carinho, a gente sente que tem profissionais que são dife- } \\
\text { rentes, mas isso é de cada um.” }\end{array}$ & \\
\hline & & $\begin{array}{l}\text { P7: “A gente tem pouco contato com os pacientes, eles vêm } \\
\text { aqui e ficam em média duas a três horas, a gente tenta fazer } \\
\text { o máximo possível, atender, se tivesse mais colaborador seria } \\
\text { bem melhor, conseguiríamos dar bem mais atenção, teria mais } \\
\text { contato com o paciente. Tem paciente que recebe muito pouca } \\
\text { atenção, quando é dia bem agitado, aí a gente dá bem pouca } \\
\text { atenção porque não tem como, nós estávamos em três funcio- } \\
\text { nárias com } 18 \text { pacientes, e você vai dar atenção como? Às vezes } \\
\text { tu nem conversa com o paciente, vê os sinais, cuida se não está } \\
\text { passando mal e dá prioridade para quem mais precisa." }\end{array}$ & \\
\hline
\end{tabular}


Quadro 2. Continuação.

\begin{tabular}{|l|l|l|l|}
\hline $\begin{array}{l}\text { Categoria / } \\
\text { Capítulo }\end{array}$ & $\begin{array}{c}\text { Unidade de } \\
\text { registro }\end{array}$ & Falas dos sujeitos & Observações \\
\hline & $\begin{array}{l}\text { P8: “É isso também, a gente não tem tempo para parar para } \\
\text { conversar com o paciente, ouvir as queixas, é: 'está com dor?', } \\
\text { 'estou', vai lá, medica e deu, não é aquela história, 'o que aconte- } \\
\text { ceu', 'como você realmente está', é mais cuidados gerais mesmo." }\end{array}$ \\
\hline $\begin{array}{l}\text { Pq: “Aqui precisaria de no mínimo mais uns dois funcionários } \\
\text { para conseguir fazer um trabalho bem-feitinho, para tu conseguir } \\
\text { prestar atenção tanto no que tu tá fazendo, quanto no paciente, } \\
\text { poder chegar e conversar com o paciente. Ás vezes o paciente } \\
\text { quer te contar a história do por que ele está numa cama pós- } \\
\text {-operatória, mas se tu parar para contar história, por que eles } \\
\text { contam detalhes, daí tu vai fazer o quê? Tu vais ficar só com } \\
\text { aquele paciente, e o restante vai ficar às vezes reclamando de dor." }\end{array}$ \\
\hline
\end{tabular}

SRPA: sala de recuperação pós-anestésica; UTI: unidade de terapia intensiva.

Quadro 3. Categorização das possibilidades.

\begin{tabular}{|c|c|c|c|}
\hline $\begin{array}{l}\text { Categoria / } \\
\text { Capítulo }\end{array}$ & $\begin{array}{l}\text { Unidade de } \\
\text { registro }\end{array}$ & Falas dos sujeitos & Observações \\
\hline \multirow[t]{3}{*}{$\begin{array}{l}\text { Capítulo } 3 \\
\text { Um cuidado } \\
\text { efetivo na SRPA: } \\
\text { possibili-dade }\end{array}$} & \multirow{3}{*}{$\begin{array}{l}\text { - Visão de coisas } \\
\text { erradas } \\
\text { - Falta de } \\
\text { funcionários } \\
\text { - Falta de apoio } \\
\text { - Abandono dos } \\
\text { pacientes } \\
\text { - Sobrecarga de } \\
\text { trabalho } \\
\text { - Equipe flexível } \\
\text { - Colaboração } \\
\text { - Insistência } \\
\text { - Auxílio de } \\
\text { monitores } \\
\text { - Falta de } \\
\text { atenção } \\
\text { - Correria } \\
\text { - Pouco cuidado } \\
\text { afetivo } \\
\text { - Olhar holístico } \\
\text { - Estresse, } \\
\text { sem tempo } \\
\text { - Descuido no } \\
\text { atendimento }\end{array}$} & $\begin{array}{l}\text { P1: “Então, quando a gente faz reunião, uma vez por mês, eu faço } \\
\text { a reunião mensal e quando tem alguma coisa nova pra passar } \\
\text { também, daí é uma reunião extra, eles sempre colocam, assim, } \\
\text { o que eles acham que não tá legal, que tem que mudar, se eles } \\
\text { percebem que o colega tá 'ah, não fez uma coisa certa' ou 'aten- } \\
\text { deu a porta de uma forma meio grosseira' ou alguma coisa assim, } \\
\text { eles vêm se reportar, e daí a gente acaba chamando o funcioná- } \\
\text { rio para conversar, né, então eles têm uma visão, assim, de coi- } \\
\text { sas que estão erradas e que têm que mudar, alguns que tu vai } \\
\text { conversar acabam não aceitando, têm um pouco de resistência, } \\
\text { 'ah mas eu sou assim, o meu jeito é assim e eu não vou mudar', } \\
\text { porque a gente está num setor assim que tu tem que se colo- } \\
\text { car no lugar do próximo, assim, porque tanto do paciente que } \\
\text { tá ali, que acordou, não sabe onde está, se já acabou, se já fez, } \\
\text { quanto o familiar que tá lá fora, porque o familiar está lá fora } \\
\text { e não sabe o que está acontecendo aqui dentro, né, então eles } \\
\text { estão lá fora, estão aflitos, então às vezes eu tenho um pouco } \\
\text { de dificuldade, assim, com quem atende a porta, né, de como } \\
\text { tratar o familiar que está lá na porta, e os pacientes aqui tam- } \\
\text { bém, é uma e outra pessoa, assim, que tem uma personalidade } \\
\text { mais fechada, que é mais difícil de lidar, mas a equipe no geral.” }\end{array}$ & \multirow{3}{*}{$\begin{array}{l}\text { - Pouca afetividade com } \\
\text { os pacientes } \\
\text { - Pouca interação com os } \\
\text { pacientes } \\
\text { - Falta de diálogo na } \\
\text { recepção dos pacientes } \\
\text { - Falta de explicações } \\
\text { sobre medicações e } \\
\text { procedimentos } \\
\text { - Falta de paciência com } \\
\text { pacientes e familiares } \\
\text { - Imposição de uma } \\
\text { conduta sem conversar/ } \\
\text { explicar ao paciente } \\
\text { - Esquecimento de } \\
\text { medidas de conforto } \\
\text { - Pouca compreensão da } \\
\text { situação do paciente } \\
\text { - Falta de proatividade de } \\
\text { alguns profissionais } \\
\text { - Pouco diálogo } \\
\text { - Falta de vigilância com } \\
\text { os pacientes. }\end{array}$} \\
\hline & & $\begin{array}{l}\text { P2: “E as mesmas cirurgias que tem durante a semana, que a } \\
\text { gente está com três enfermeiras, a coordenadora e mais duas, no } \\
\text { final de semana só tem uma para dar conta. Às vezes tem falta } \\
\text { de funcionários também. A gente não pode tomar a iniciativa de } \\
\text { fazer as coisas, até a gente sabe, mas não pode estar fazendo } \\
\text { até uma medicação porque o médico tem que vir avaliar, tem } \\
\text { que prescrever, né, porque sem estar prescrito não pode fazer." }\end{array}$ & \\
\hline & & $\begin{array}{l}\text { P3: “Sim, a gente encontra várias dificuldades para cuidar do } \\
\text { paciente. Se um paciente é tranquilo, beleza, a gente dá jeito, } \\
\text { tem a enfermeira sempre perto, é mais de uma semana que a } \\
\text { gente só tem uma enfermeira no bloco, então é mais difícil, né. } \\
\text { Então a gente encontra talvez um pouco de dificuldade na falta } \\
\text { desse apoio, né, falta talvez de enfermeira no final de semana } \\
\text { para ajudar a gente. No caso de emergência, o médico vinha }\end{array}$ & \\
\hline
\end{tabular}


Quadro 3. Continuação.

\begin{tabular}{|l|l|l|}
\hline $\begin{array}{l}\text { Categoria / } \\
\text { Capítulo }\end{array}$ & $\begin{array}{c}\text { Unidade de } \\
\text { registro }\end{array}$ & \multicolumn{1}{c|}{ Falas dos sujeitos } \\
\hline & $\begin{array}{l}\text { ajudar a gente também, mas é um pouco mais difícil, se temos } \\
\text { pacientes de UTI, o pessoal de anestesia já não faz mais a parte } \\
\text { de cuidar de paciente de UTI, daí liga pra UTI, também não tem } \\
\text { ninguém para vir, liga para o P2, liga para não sei o que, é meio } \\
\text { que abandonado os pacientes. Então, essa parte que a gente } \\
\text { encontra mais dificuldade. 'Eu venho, faço nossa rotina', nossa } \\
\text { seria muito melhor, mas assim é mais difícil nós cuidar, porque às } \\
\text { vezes dá uma emergência, a gente liga para um, liga para outro, } \\
\text { já aconteceu. Então se tivesse alguém nessa parte para apoiar, } \\
\text { seria muito melhor nosso trabalho e talvez até o paciente sairia } \\
\text { mais satisfeito, não correria tanto risco também." }\end{array}$ \\
\hline
\end{tabular}

P4: “A equipe se ajuda nas tarefas, porém falta de funcionários, sobrecarga quando tem que assumir paciente de UTI e mais três ou quatro pacientes cirúrgicos."

P5: “É uma equipe boa, se ajuda bastante, não tem esse lado de uma não querer ajudar a outra, ou se tu pedes uma ajuda, os colegas não se negam, é uma equipe bem flexível para trabalhar."

P6: “É um conjunto, aquela parte de receber o paciente, do colega estar ali, de a gente estar ali, fazer o trabalho da gente, aquela coisa do anestesista colaborar, tipo quando está com dor dar a medicação, quando o paciente está liberado (fechou o horário, paciente está bem, sinais vitais tudo certinho, sem sangramento) o anestesista vir, às vezes a gente tem que ir duas ou três vezes procurar, às vezes tem uns que não gostam de ficar liberando cada pouco, de duas em duas horas vir aqui e avaliar. Até um tempo atrás era assim, agora que mudou. De dia, a gente está mais junto com os médicos, de noite fica o plantão, no caso, de dia cada um está em uma sala, e de noite daí fica o plantão para avaliar e liberar. 0 que mais a gente nota é que os médicos se sentem mais seguros de deixar o paciente aqui e não mandar para o quarto. Eu acho, assim, que a recuperação é um pós-operatório, não é UTI. Se é uma emergência, faz a cirurgia, tem leito, tem tudo, mas se é uma coisa que dá para esperar, tipo, esperar um leito na UTI para fazer cirurgia, porque aqui a gente faz, cuida o paciente de UTI, faz tudo, só que o paciente de UTI precisa mais cuidados e às vezes está cheio de pós-operatório e já não podemos dar o cuidado que precisa, já ficamos com cinco, seis pacientes de UTI aqui. De dia são sete funcionários, noite dois para a demanda."

P7: “Gosto muito porque esses monitores multiparâmetros ajudam bastante, porque você já não dá muita atenção, então esses monitores são nossos olhos. Como fragilidades, essas mães que ficam aqui com as crianças, as crianças são muito frágeis, não que a gente não queira atender, mas eu acho que não deveriam ficar aqui na recuperação junto com outras operações, outras patologias. 0 cuidado a gente faz, mas tem muito a desejar."

P8: “Com certeza, eu acho que mais é a questão da fragilidade mesmo, que é a falta do cuidado mesmo afetivo, eu também acho, e no geral também, no olhar holístico do paciente, eu acho que falta muito, mas porque tu não tens tempo, tu não dás conta, é uma demanda muito grande para pouca gente, porque assim, lá fora é uma funcionária para cuidar de nove, 11 pacientes, mas não são pós-operatório, se o paciente vai ficar mal, é nas duas, três, quatro primeiras horas, é o horário que ele mais precisa. Se tu olhar ali, os sinais são de zero, 15, 30, 45 minutos, e nem sempre tu consegues 
Quadro 3. Continuação.

\begin{tabular}{|c|c|c|c|}
\hline $\begin{array}{l}\text { Categoria / } \\
\text { Capítulo }\end{array}$ & $\begin{array}{l}\text { Unidade de } \\
\text { registro }\end{array}$ & Falas dos sujeitos & Observações \\
\hline & & $\begin{array}{l}\text { fazer isso, a maioria das vezes não consegues fazer. As primei- } \\
\text { ras horas é que inspiram o maior cuidado, e a gente não conse- } \\
\text { gue fazer como tem que ser feito, não tem como, é pouca gente." }\end{array}$ & \\
\hline & & $\begin{array}{l}\text { P9: “Eu acho que é isso, falta de funcionário, tinha que ter mais } \\
\text { funcionário, no caso, pra gente poder fazer melhor o nosso tra- } \\
\text { balho, em todos os sentidos, tanto no cuidar do paciente, quanto } \\
\text { cuidar da gente, às vezes, né, porque às vezes a gente fica sobre- } \\
\text { carregado, fica estressada, e às vezes tu deixa de atender bem } \\
\text { o paciente pelo próprio estresse, por falta de tempo, gerando o } \\
\text { estresse, e aí você acaba às vezes, tipo, você não consegue dar } \\
\text { atenção ao paciente, desleixo talvez, mas não porque você quer, } \\
\text { por falta de tempo. É aquela sensação de você querer fazer e não } \\
\text { conseguir. Você sabe que poderia fazer, mas tu não consegues } \\
\text { fazer porque tu não tens o tempo de ficar ali junto com eles." }\end{array}$ & \\
\hline
\end{tabular}

SRPA: sala de recuperação pós-anestésica; UTI: unidade de terapia intensiva.

\section{DISCUSSÃO}

Cuidar do paciente na SRPA é uma das principais preocupações e responsabilidades da equipe de enfermagem, já que envolve o ser humano em situações de vulnerabilidade, ultrapassando os limites técnicos, para abranger a dimensão terapêutica. Nesse sentido, o cuidado humanizado percebe o paciente em sua totalidade e, dessa forma, os profissionais podem ser capazes de identificar os sinais mais subjetivos que o paciente expressa sobre seu estado de saúde ${ }^{9,10}$.

\section{Atuação da equipe de enfermagem em relação às normas e protocolos da sala de recuperação pós-anestésica}

Diante do contexto histórico do cuidado prestado ao paciente pela equipe de enfermagem na SRPA, na atualidade, o ato de cuidar substituiu a crença empírica por conhecimentos e evidências científicas, promovendo maior segurança nos cuidados ao paciente pós-cirúrgico. Tendo em vista as especificidades de cada procedimento cirúrgico, as normas e os protocolos assistenciais do setor têm como objetivos direcionar e qualificar o cuidado, possibilitando a obtenção de resultados positivos e, dessa forma, estimulando a equipe de enfermagem a evoluir por meio da adesão a conhecimentos científicos em sua prática profissional ${ }^{9}$.

A equipe de enfermagem reconhece a importância do uso de protocolos assistenciais para o cuidado e, apesar do fluxo intenso do setor, a prática baseada em evidências aparece na atuação dos profissionais, mesmo diante de algumas dificuldades impostas pelo cotidiano da profissão.

Cabe destacar que as normas e os protocolos são importantes, porém na vivência com a equipe se percebeu que, mesmo com a implantação e os processos de capacitação propostos pela equipe de treinamento do hospital sede do estudo, a sequência dos cuidados, considerando-se os protocolos, não ocorre dessa maneira ${ }^{10}$. A evolução ocorre em forma de anotação simples, bem como a avaliação. Destacamos que a sistematização da assistência de enfermagem perioperatória (SAEP) não se efetiva. Portanto, não se tem uma análise integral do paciente.

Levando em consideração o contexto abordado anteriormente, é essencial que o profissional de enfermagem faça uma análise criteriosa do paciente durante sua permanência na SRPA, especialmente porque esse é o período mais crítico do pós-operatório, no qual o paciente pode apresentar instabilidades ${ }^{10}$.

De maneira geral, em alguns turnos foi observado que existia um cuidado mais atento, tecnicamente algumas questões são observadas, porém o cuidado com a higiene e o conforto do paciente não ocorre. Nesse sentido, percebeu-se também, de acordo com os relatos, que durante todo o período perioperatório o paciente não recebe um cuidado sistematizado, visto que, em muitos casos, chega à SRPA com algumas complicações do transoperatório, por vezes negligenciadas.

Nota-se a falta de comunicação entre a equipe, a não continuidade do cuidado e, consequentemente, a não sistematização, apesar da existência de protocolos que sustentam e reafirmam sua importância. Com isso, ocorre um rompimento no processo de cuidar, criando um cenário de responsabilização de outros setores. Alguns diálogos denotam a 
implantação de novos protocolos, como o checklist de cirurgia segura, que visam à segurança do paciente e que objetivam a minimização de agravos, porém esses protocolos não são efetivamente seguidos pela equipe, o que torna os pacientes vulneráveis durante o processo.

Ao considerar o olhar da segurança do paciente, tanto as normas que orientam o trabalho profissional quanto a SAEP compreendem o mesmo propósito. A SAEP trabalha com o intuito de organizar e direcionar a atuação dos profissionais de enfermagem, relacionada ao cuidado dos pacientes na sua totalidade ${ }^{11}$.

A equipe de enfermagem reconhece a importância do trabalho em equipe no que tange ao cuidado dos pacientes, reconhecendo que o cotidiano, muitas vezes, inviabiliza as ações, mas com a colaboração dos profissionais se torna possível o cuidado direcionado aos pacientes em todos os aspectos, na intenção de melhor atender a eles.

Observamos que a equipe procura se adaptar ao fluxo do setor e à estrutura física para melhor atender os pacientes. Porém, ficou evidente que essa redistribuição de pacientes não possibilitou um cuidado mais atento. Em dias de maior fluxo, percebia-se que muitas demandas do paciente atrasavam, como medicações, aferição de sinais vitais, entre outros procedimentos necessários.

Estudo recente vem ao encontro desses dados quando evidencia que a omissão do cuidado se caracteriza por ações essenciais não desempenhadas ou realizadas de maneira parcial, resultados que corroboram os de outro estudo realcionado e esse tema ${ }^{12}$. Para as autoras, o comprometimento da equipe para fornecer cuidados de enfermagem de qualidade, de acordo com as necessidades específicas de cada paciente e em tempo hábil, torna-se fundamental ${ }^{12}$.

Cabe destacar que os dados deste estudo se alinham aos encontrados em outras pesquisas, tendo em vista que as principais razões identificadas para a omissão do cuidado foram problemas relacionados ao número inadequado de pessoal, situações de urgência dos pacientes e aumento inesperado de volume ou gravidade do seu quadro, além de recursos materiais e equipamentos não disponíveis ou inadequados ao uso ${ }^{12}$.

A percepção positiva da equipe de enfermagem em relação ao seu ambiente de trabalho está associada com a menor frequência de omissão de cuidado. Em virtude da dinâmica do setor, é fundamental que a equipe de enfermagem trabalhe de forma integrada, afinal essa é uma estratégia que permite articular com precisão as ações a serem desenvolvidas, baseadas nos protocolos assistenciais instituídos, com vistas à obtenção de melhores resultados no que tange à qualificação do cuidado direcionado ao paciente ${ }^{13}$.
A SRPA é uma unidade específica, que desenvolve cuidados intensivos direcionados ao POI, exigindo um olhar atento e perspicaz da equipe em relação às diversas especificidades avaliadas no paciente pós-cirúrgico. Com isso, objetiva-se a análise criteriosa da situação de saúde do paciente para posterior articulação do cuidado, de acordo com o que ele necessita ${ }^{14}$.

\section{Um olhar para a afetividade no cuidado de enfermagem na sala de recuperação pós-anestésica}

É sabido que a SRPA é um ambiente dinâmico, com grande rotatividade de pacientes, restrito ao acesso e com a necessidade de atenção aos pacientes e aos seus familiares. A afetividade no cuidado de enfermagem não exige nenhuma ferramenta que ensine um passo a passo, mas depende da conduta e da maneira de conduzir o cuidado de cada profissional da equipe. Ser afetivo e desempenhar um trabalho igualmente afetivo exige a constante lapidação de nossos valores enquanto colaboradores de uma equipe e como pessoas. A compreensão da situação do paciente, o colocar-se no lugar dele, envolvendo-o no cuidado e sentindo-se bem com a atividade que se exerce são alguns aspectos que qualificam o atendimento de enfermagem ${ }^{10}$.

A equipe deve desenvolver ações que visem à promoção da qualidade no cuidado direcionado para as especificidades de cada paciente, reduzindo possíveis riscos pós-operatórios. Para isso, os profissionais necessitam desenvolver um olhar crítico, atento e sensível sobre o paciente, identificando situações que requeiram intervenção ${ }^{15}$.

A equipe trabalha de maneira conjunta para atender os pacientes, minimizando desconfortos advindos do procedimento anestésico-cirúrgico. Por outro lado, no decorrer da observação de campo, indicaram-se diversas falhas com relação às solicitações dos pacientes, associadas à equipe e à sua atenção e seu atendimento às demandas. Frequentemente, os eventos adversos que ocorrem no ambiente hospitalar são relacionados a iatrogenias humanas, porém, para uma análise mais detalhada do paciente, é necessário considerar as condições ambientais das práticas de ações de cuidado, os aspectos estruturais e a complexidade desse paciente atendido ${ }^{16}$.

$\mathrm{O}$ aspecto mais relevante citado e que afeta diretamente a qualidade do cuidado é a falta de funcionários. Em contrapartida, na vivência com a equipe do setor, percebeu-se que, diante da grande demanda, a equipe não conseguia efetivar um cuidado seguro, afetivo e eficaz para todos os pacientes.

$\mathrm{Na}$ convivência com a equipe, foi perceptível que muitos deixavam a desejar em alguns aspectos importantes no 
cuidar do paciente, como: paciência em sanar dúvidas, carinho e afetividade ao direcionar o cuidado, empatia ao receber o paciente no setor, entre outros aspectos que interferiam na recuperação dos pacientes e, consequentemente, no seu tempo de permanência no setor. Nesse sentido, por se tratar de um ambiente dinâmico, os profissionais da SRPA encontram dificuldades em estabelecer vínculo com os pacientes, seja pelo reduzido tempo de permanência, seja pela falta de tempo para se dedicar, por causa do grande número de pacientes a serem atendidos, o que impede que se estabeleçam relações de proximidade e atenção adequadas.

A SRPA é um ambiente que permite pouca criação de vínculo entre profissionais e pacientes. Em contrapartida, no decorrer da vivência das pesquisadoras, percebeu-se que é possível estabelecer um contato mais próximo com o paciente, pois o profissional enfermeiro necessita do diálogo para nortear a recuperação e as condutas a serem tomadas. Diante do exposto, o cotidiano da equipe de enfermagem dificulta a criação de vínculo entre profissionais e pacientes, porém não se configura como algo imutável, tendo em vista os benefícios, tanto para o profissional como para o paciente, de saber que sua atuação se encontra vinculada a um dos pilares da sua profissão.

\section{Um cuidado efetivo na sala de recuperação pós-anestésica: possibilidades?}

Quando se fala em cuidado na SRPA, abre-se um amplo leque de possibilidades para a equipe de enfermagem. As tecnologias de informação têm sido amplamente utilizadas no que diz respeito ao armazenamento e ao acesso a dados que podem tornar a assistência mais dinâmica e efetiva. Essa tecnologia, pautada em protocolos que sustentam o desenvolvimento da profissão, por exemplo, é responsável por potencializar o raciocínio clínico e a tomada de decisão dos profissionais, tendo em vista que o cuidado sistematizado permite identificar e tratar precocemente possíveis complicações do processo anestésico-cirúrgico ${ }^{17}$.

A equipe de enfermagem compreende a importância de um cuidado efetivo ao paciente, elencando mudanças necessárias para melhor atendê-lo na SRPA e a seus familiares na sala de espera, trabalhando de maneira integrada na busca pela resolução das dificuldades encontradas no cotidiano do trabalho.

Os profissionais reconhecem a necessidade de mudança em alguns aspectos, o que se comprovou pelas pesquisadoras na vivência do setor. Nesse contexto, quando a equipe profissional se encontra diminuída em número e na qualidade do serviço oferecido, a afetividade com a qual o cuidado é desenvolvido também é afetada. Ser afetivo com o paciente ultrapassa os limites do carinho, do afeto propriamente dito, mas encontra-se no diálogo, no toque respeitoso, no olhar atento e compreensivo à situação do paciente. Quando os profissionais, por algum motivo, não estão com esse foco, o cuidado prestado ao paciente torna-se apenas uma atividade tarefeira, omitindo a real essência do cuidado de enfermagem na SRPA e tornando o cotidiano da equipe monótono ${ }^{15}$.

Os pacientes pós-operatórios possuem potencial risco de complicações na SRPA, muitas vezes evitáveis, desde que detectadas precocemente. Logo, ao adentrar no setor, o paciente é vigiado com o auxílio de monitor multiparâmetros que informa os profissionais sobre possíveis alterações dos sinais vitais, o que é imprescindível para a recuperação segura do paciente ${ }^{18}$.

No que se refere ao vínculo estabelecido entre os profissionais da equipe de enfermagem no ambiente de trabalho, a demanda exige que exista uma relação de cumplicidade, para que consigam atender o fluxo de pacientes e para que o cuidado seja direcionado minimamente às necessidades básicas de cada paciente que passa pelo setor ${ }^{19}$.

\section{CONSIDERAÇÕES FINAIS}

A aplicação dos protocolos assistenciais específicos da SRPA contribui para a sistematização e a segurança do cuidado prestado aos pacientes, tendo em vista a complexidade do atendimento nesse setor durante o POI, entretanto é conveniente destacar que a pesquisa mostrou resistência dos colaboradores quanto ao uso dos protocolos assistenciais padrão e ao uso mínimo de registros sistematizados durante o cuidado prestado aos pacientes. Para que o atendimento possa ser sistematizado de acordo com cada necessidade, faz-se necessário o uso de protocolos, como a avaliação $\mathrm{ABC}$ na admissão inicial do paciente, o checklist de cirurgia segura, o índice de Aldrete e Kroulik, a escala de sedação de Ramsey, o índice de Steward e a escala da dor, que são decisivos no momento da alta do paciente. Em decorrência da grande demanda do setor, apresentam-se, ainda, outros fatores que prejudicam a efetividade do cuidado, como o quantitativo de profissionais inadequado.

Nessa perspectiva, a SRPA não se configura apenas como setor em que o paciente aguarda passarem os efeitos da anestesia, devendo ser reconhecida como ambiente dotado de criticidade e complexidade, onde os cuidados multiprofissionais devem ser intensivos, de modo a garantir a continuidade no tratamento dos pacientes e promover êxito do 
procedimento cirúrgico realizado. Assim, a pesquisa desenvolvida e socializada apresenta a relevância do emprego de cuidados seguros em todos os momentos do período operatório, principalmente no POI.

Concluímos com o desejo de que outras pesquisas sejam desenvolvidas no setor, para que continue sendo reafirmada a importância da utilização dos protocolos assistenciais como norteadores do cuidado, buscando a segurança do paciente e a evolução da enfermagem enquanto profissão e ampliando essa conquista para outros serviços de saúde que tenham como meta aprimorar a qualidade do cuidado desenvolvido e seu êxito.

\section{REFERÊNCIAS}

1. Campos MPA, Dantas DV, Silva LSL, Santana JFNB, Oliveira DC, Fontes LL. Complicações na sala de recuperação pós anestésica: uma revisão integrativa. Rev SOBECC. 2018;23(3):160-8. https:// doi.org/10.5327/Z1414-4425201800030008

2. Portela LVM. As intervenções de enfermagem e sua importância na sala de recuperação pós-anestésica. Rev Cient Fac Mais. 2018 [acessado em 22 jul. 2019];12(1):76-85. Disponível em: http://revistacientifica.facmais.com. br/wp-content/uploads/2018/06/5.-AS-INTERVEN\%C3\%87\%C3\%95ESDE-ENFERMAGEM-E-SUA-IMPORT\%C3\%82NCIA-NA-SALA-DERECUPERA\%C3\%87\%C3\%830-P\%C3\%93S-ANEST\%C3\%89SICA.pdf

3. Resende C, Torralba R. Editorial. Dossiê corporeidade. Fractal Rev Psicol. 2017;29(2):87-8. https://doi.org/10.22409/1984-0292/v29i2/2500

4. Koch TM, Aguiar DCM, Moser GAS, Hanauer MC, Oliveira D, Maier SRO. Momento anestésico-cirúrgico: transitando entre o conhecimento dos(as) enfermeiros(as) e o cuidado de enfermagem. Rev SOBECC. 2018;23(1):7-13. https://doi.org/10.5327/Z1414-4425201800010003

5. Santos CFAR, Brasileiro ME. Protocolos necessários a assistência de enfermagem em sala de recuperação pós-anestésica: revisão integrativa. Rev Cient Multidisc Núcleo Conhecim. 2018 [acessado em 20 jul. 2019];3(9):98-120. Disponível em: https://www. nucleodoconhecimento.com.br/saude/sala-de-recuperacao

6. Minayo MCS. Pesquisa social: teoria, método e criatividade. 21 a. ed. Petrópolis: Vozes; 2001.

7. Geertz C. Uma descrição densa: por uma teoria interpretativa da cultura. Rio de Janeiro: Guanabara Koogan; 2008. 323 p.

8. Bardin L. Análise de conteúdo. 4a. ed. Lisboa: Edições 70; 2010.

9. Klein S. Segurança do paciente na sala de recuperação pós-anestésica: um cuidado desvelado nesse território de passagem [trabalho de conclusão de curso]. Chapecó: Universidade Federal da Fronteira Sul; 2014 [acessado em 20 jul. 2019].76 p. Disponível em: https://rd.uffs.edu.br/handle/prefix/1343

10. Val JS. Humanização do enfermeiro na sala de recuperação pós-anestésica [trabalho de conclusão de curso]. Assis: Fundação Educacional do Município de Assis; 2012 [acessado em 20 jul. 2019]. 42 p. Disponível em: https://cepein.femanet.com.br/BDigital/arqTccs/0921250034.pdf

11. Gutiérrez MGR, Morais SCRV. Systematization of nursing care and the formation of professional identity. Rev Bras Enferm. 2017;70(2):455-60. http://dx.doi.org/10.1590/0034-7167-2016-0515
12. Dutra CKR, Salles BG, Guirardello EB. Situations and reasons for missed nursing care in medical and surgical clinic units. Rev Esc Enferm USP. 2019;53:e03470. http://dx.doi.org/10.1590/S1980-220X2017050203470

13. Laccort AA, Oliveira GB. A importância do trabalho em equipe no contexto da enfermagem. Rev UNINGÁ Rev. 2017 [acessado em 22 jul. 2019];29(3):6-10. Disponível em: http://revista.uninga.br/index. php/uningareviews/article/view/1976/1572

14. Dill MCP, Arboit EL, Kaefer CT, Arboit J. Percepções acerca de um instrumento para avaliação e alta da sala recuperação pósanestésica. Rev Fund Care Online. 2018;10(3):711-9. http://dx.doi. org/10.9789/2175-5361.2018.v10i3.711-719

15. Bonetti AEB, Girardello DTF, Coneglian ALA, Egevardt D, Batista J, Cruz EDA. Assistência da equipe de enfermagem ao paciente em sala de recuperação pós-anestésica. Rev Enferm UFSM. 2017 [acessado em 22 jul. 2019];7(2):193-205. Disponível em: https://periodicos. ufsm.br/reufsm/article/view/26840/pdf https://doi.org/10.5902/2179769226840

16. Moraes KB, Riboldi CO, Silva KS, Maschio J, Stefani LPC, Tavares $J P$, et al. Transferência do cuidado de pacientes com baixo risco de mortalidade no pós-operatório: relato de experiência. Rev Gaúcha Enferm. 2019;40(Núm. Esp.):e20180398. https://doi. org/10.1590/1983-1447.2019.2018039

17. Kikuchi AMP. SRPA para cuidados de enfermagem ao paciente em recuperação pós-anestésica submetido à cirurgia vascular [trabalho de conclusão de curso]. Florianópolis: Centro de Ciências da Saúde; 2018 [acessado em 20 jul. 2019]. 65 p. Disponível em: https://repositorio. ufsc.br/bitstream/handle/123456789/187147/TCCFinalOFICIAL2. pdf? sequence= 1 \&isAllowed=y

18. Santos MR, Santos JJ, Santana NA, Melo IA, Naziazeno SDS. A importância da assistência de enfermagem na sala de recuperação pós-anestésica: visão dos monitores em enfermagem cirúrgica. In: Anais do 1. Congresso Internacional de Enfermagem; 2017; Tiradentes, Brasil. Tiradentes: Universidade Tiradentes; 2017 [acessado em 20 jul. 2019]. p. 1-4. Disponível em: https://eventos.set.edu.br/index. php/cie/article/view/5774/2007

19. Araújo EAG, Paula WKA, Oliveira LAF, Arruda ACV. Sistematização da assistência de enfermagem na sala de recuperação pós-anestésica. Rev SOBECC. 2011 [acessado em 20 jul. 2019];16(3):43-51. Disponível em: https://revista.sobecc.org.br/sobecc/article/ view/207/pdf-a 